\title{
Clinical Benefits Over Time Associated with Use of V-Go Wearable Insulin Delivery Device in Adult Patients with Diabetes: A Retrospective Analysis
}

\author{
David Sutton · Charissa D. Higdon · Carla Nikkel (D) - Karrie A. Hilsinger
}

Received: March 18, 2018 / Published online: May 10, 2018

(C) The Author(s) 2018

\begin{abstract}
Introduction: Advances in insulin delivery have improved outcomes in patients with diabetes. This study evaluated the impact of $\mathrm{V}-\mathrm{Go}^{\circledR}$ Wearable Insulin Delivery device on glycated hemoglobin (A1C) and insulin total daily dose (TDD) in patients with diabetes not achieving glycemic targets.

Methods: Electronic medical record data was obtained for adult patients with A1C $>7 \%$ treated at a multicenter endocrine practice who initiated V-Go between August 2012 and August 2015. Data were collected at baseline and for up to four follow-up visits, and were analyzed overall, stratified by insulin use at baseline, and for patients prescribed a basal-bolus insulin regimen delivered by multiple daily injections (MDI) at baseline. Economic evaluations were conducted in patients previously prescribed MDI regimens.
\end{abstract}

Enhanced digital features To view enhanced digital features for this article go to https://doi.org/10.6084/ m9.figshare.6148577.

D. Sutton · C. D. Higdon

Northeast Florida Endocrine and Diabetes

Associates, LLC, Jacksonville, FL, USA

C. Nikkel $(\bowtie) \cdot$ K. A. Hilsinger

Valeritas, Inc., Bridgewater, NJ, USA

e-mail: cnikkel@valeritas.com
Results: Patients $(N=103)$ were evaluated after a mean of $2,6,10$, and 14 months of V-Go use. Baseline glycemic control was poor (A1C > 9\%) in $59 \%$ of patients. Significant, sustained reductions in $\mathrm{A} 1 \mathrm{C}$ compared with baseline were observed at every visit $(p<0.0001)$, with mean \pm SE decrease of $1.67 \pm 0.24 \%$ after 14 months. For patients prescribed insulin at baseline $(n=80)$, TDD was significantly reduced at all visits $(p<0.0001)$, with mean $\pm \mathrm{SE}$ reduction of $17 \pm 4.5$ units/day at 14 months. Patients previously prescribed MDI therapy $(n=58) \quad$ benefited from $1.53 \pm 0.31 \%$ $(p<0.001)$ A1C reduction and TDD decrease of $30 \pm 5$ units/day after 14 months. Direct pharmacy wholesale acquisition costs for diabetes therapeutics were reduced by $\$ 25.00 /$ patient/month.

Conclusion: Use of V-Go was associated with improved glycemic control and decreased TDD. For patients previously prescribed basal-bolus MDI therapy, switching to insulin therapy with V-Go resulted in pharmacy cost savings based on wholesale acquisition costs. V-Go offers an efficacious method of insulin delivery that improves outcomes in patients and can reduce costs.

Funding: Valeritas, Inc.

Keywords: Basal-bolus; Diabetes; Glycemic control; Insulin delivery; Multiple daily injections; V-Go 


\section{INTRODUCTION}

In the USA, approximately 1 in every 11 adults has diabetes, with dramatic increases in prevalence expected over the next few decades [1-4]. Despite the availability of many non-insulin glucose-lowering medications (NIGLM), 50\% of patients with diabetes fail to achieve A1C targets [5]. Insulin remains the most potent glucose-lowering agent with the highest potential to achieve glycemic control [6, 7]. However, over $70 \%$ of physicians report that their typical patient does not use insulin as prescribed [8]. Patients as well as physicians report the two most common difficulties that impact adherence are the number of daily injections required and taking insulin at the prescribed time or with meals on a daily basis [8].

Patients with poor glycemic control are at risk of microvascular complications, and costs are two to eight times higher in patients with poor glycemic control or complications $[9,10]$. A key to improving glycemic control is to understand why patients remain poorly controlled despite insulin therapy [11]. It is important to differentiate between a prescribed regimen that is inadequate and needs to be adjusted, and an appropriate insulin regimen that is not being adhered to.

Advances in insulin delivery over time have addressed many patient concerns and can improve acceptance and adherence [12]. Prefilled disposable insulin pens, which were introduced in 1985 [13], are associated with fewer hypoglycemia-related visits and lower overall costs than vial and syringe administration [14]. Another advancement was the fully mechanical basal-bolus insulin delivery device, an alternative to insulin pen therapy that allows delivery of basal-bolus therapy with fewer daily insulin injections.

V-Go ${ }^{\circledR}$ (Valeritas, Inc., Bridgewater, NJ) is a wearable basal-bolus insulin delivery device indicated for patients 21 years of age and older requiring insulin that was launched in the USA in 2012. It is fully mechanical with no tubing or electronics, and it does not require any programming. V-Go delivers a continuous basal infusion $(20,30$, or 40 units/24 h) and allows for up to 36 additional units of insulin for mealtime dosing in 2-unit increments [15]. V-Go is filled with U-100 fast-acting insulin (e.g., insulin lispro or insulin aspart) and is worn like a patch on the skin using a hypoallergenic and latex-free adhesive. V-Go is designed to be replaced every $24 \mathrm{~h}$ and is fully disposable. The push of a button inserts a 4.6$\mathrm{mm}, 30$-gauge stainless steel needle subcutaneously and starts the delivery of the continuous preset basal rate of insulin. Mealtime bolus insulin doses are administered on-demand by pressing the bolus-ready button and the bolusdelivery button (Fig. 1).

Previous studies showed that switching patients from traditional insulin delivery modes to V-Go has been associated with significantly improved glycemic control [16-20]; however, durability over time of the impact on $\mathrm{A} 1 \mathrm{C}$ and insulin total daily dose (TDD) has not been assessed. Further, economic implications have not been well defined in patients previously administering a basal-bolus regimen and switched to V-Go. Therefore, the objective of this retrospective study was to evaluate clinical outcomes over time and associated direct pharmacy costs of diabetes therapy in patients with sub-optimally controlled diabetes who were naïve to insulin therapy or who transitioned from other traditional modes of insulin delivery to V-Go.

\section{METHODS}

A query of an electronic medical records (EMR) database from a large, multicenter endocrine practice system (Northeast Florida Endocrine and Diabetes Associates, Jacksonville, FL) identified patients with diabetes who initiated V-Go between August 2012 and August 2015. No educational initiatives, special procedures, training, and/or practice changes were implemented during the study period. Adult patients 21 years of age and older with a diabetes diagnosis [type 1 or type 2 diabetes mellitus (T2DM)], baseline A1C $>7 \%$ within 90 days prior to V-Go initiation, and a minimum of one subsequent $\mathrm{A} 1 \mathrm{C}$ lab measurement on $\mathrm{V}$-Go were eligible for inclusion. Patients who were 


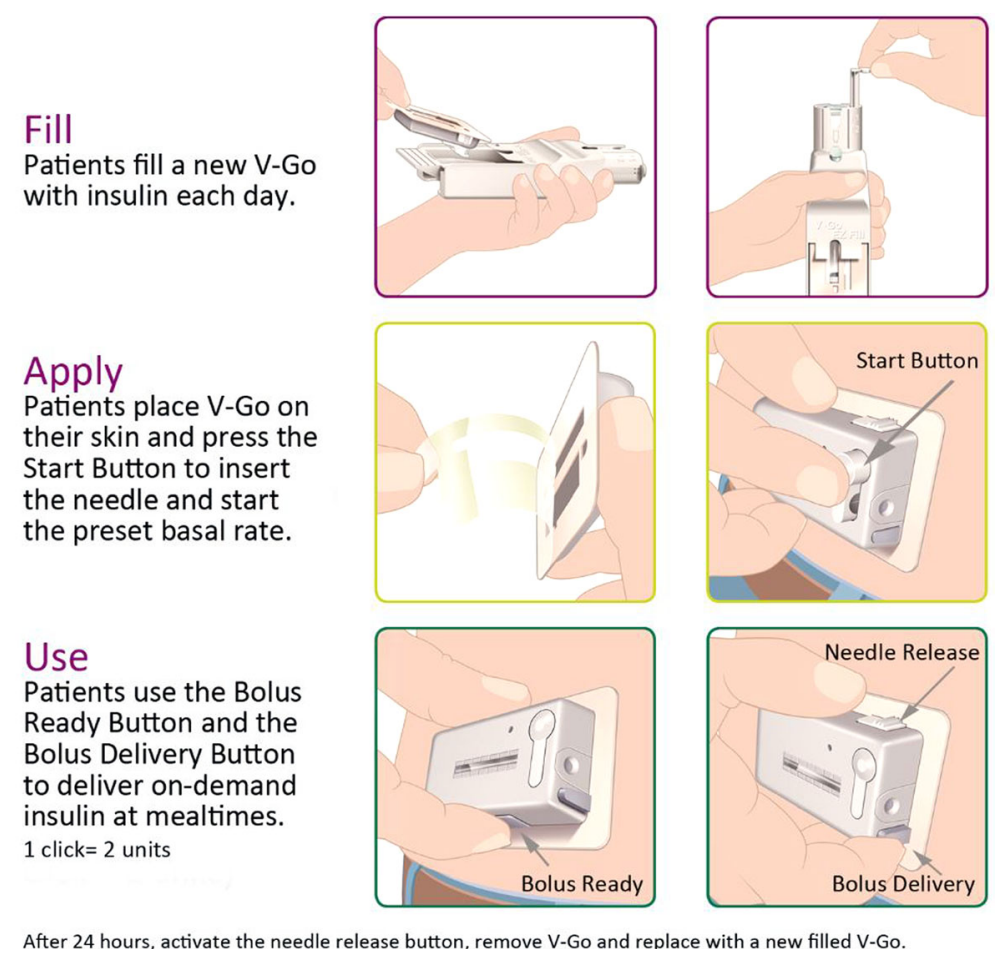

Fig. 1 V-Go Wearable Insulin Delivery device

prescribed U-500 regular insulin or an electronic insulin pump, receiving chemotherapy, taking medications for infectious or immune-related diseases associated with increased insulin resistance, or who were pregnant or lactating were excluded from the study. Additionally, patients prescribed insulin were excluded if there was insufficient information in the EMR to determine TDD at baseline or during V-Go therapy. The study was reviewed and approved by Allendale Investigational Review Board and a waiver of patient consent granted. All procedures performed in the study were in accordance with the ethical standards of the institutional and/or national research committee and with the 1964 Declaration of Helsinki and its later amendments.

A1C measurements, insulin dosing, insulin regimens (e.g., basal, premix, basal-bolus), weight, NIGLM, and patient-reported hypoglycemic events were obtained from the EMR records at baseline and for up to four follow-up office visits (OVs) where an A1C measurement was documented. Primary outcome measures included changes in $\mathrm{A} 1 \mathrm{C}$ and insulin dosing from baseline. Secondary outcome measures included changes in weight and patient-reported hypoglycemia in all patients and economic analyses for patients prescribed basalbolus multiple daily injections (MDI) therapy prior to V-Go.

\section{Data Analysis}

Means and standard deviations (SD) were reported for continuous measures and frequency and percentages were reported for categorical measures. Statistical significance between baseline and follow-up values was assessed using the paired $t$ test for continuous measures and McNemar's test for categorical measures. Missing data for continuous variables were imputed using the multiple imputation feature in SPSS and pooled data were used to express changes from baseline. Outcomes were assessed for the overall population and stratified by insulin use overall and basal-bolus MDI use at baseline. All statistical analyses were performed using SPSS v. 25.0 (Armonk, NY). 
$p$ values less than 0.05 were considered to be significant.

Direct diabetes-related pharmacy costs before V-Go in patients previously prescribed basal-bolus therapy and after a mean of 14 months on V-Go were calculated to assess cost impact to the pharmacy budget. All insulin costs were normalized by calculating a 30-day insulin requirement based on the prescribed TDD and multiplying the monthly insulin dose in units by the unit cost of the prescribed insulin. Costs associated with mode of insulin delivery (pen needles, syringes, or V-Go) were also included. All concomitant NIGLM were captured; however, only branded medications were accounted for in pharmacy cost calculations. Costs of all glucose-lowering medications were based on published wholesale acquisition costs in 2018 US dollars.

\section{RESULTS}

Two hundred and twelve patients were identified by the database query, and 103 of these patients met all inclusion criteria and no exclusion criteria and were enrolled in the study. Primary reasons for ineligibility included use of U-500 insulin (20\%), patient did not return to the clinic after V-Go initiation (16\%), incomplete data in electronic records (13\%), or a baseline A1C was not available within 90 days of V-Go initiation (12\%). Baseline clinical characteristics for enrolled patients are shown in Table 1 and baseline prescribed treatment regimens are shown in Table 2. Of the 103 patients enrolled, $22 \%$ were insulin-naïve and $78 \%$ were switched to V-Go from prior insulin regimens, with the majority $(n=58)$ prescribed a basal-bolus regimen delivered by MDI at baseline. Almost all patients (96\%) were diagnosed with T2DM. Nearly $60 \%$ of patients had an $\mathrm{A} 1 \mathrm{C}>9.0 \%$ at baseline. The mean $\pm \mathrm{SD}$ duration of V-Go therapy at OV1 was $2.0 \pm 1.2$ months, at OV2 $5.8 \pm 2.8$ months, at OV3 $10.1 \pm 4.0$ months, and at OV4 $14.2 \pm 4.9$ months. Therefore results will be referred to henceforth as the 2-, 6-, 10-, and 14-month visits.

\section{Clinical Outcomes}

In the overall cohort $(n=103)$, significant mean reductions in A1C were observed at every follow-up time point compared to baseline (Fig. 2), with $82 \%$ of patients maintaining an $\mathrm{A} 1 \mathrm{C}$ below baseline at study end. The percentage of patients at high risk (A1C $>9.0 \%)$ was reduced from $59 \%$ at baseline to $26 \%(p<0.001)$ at the 14 -month visit. In addition, $50 \%$ of patients overall achieved an A1C $<8 \%$ with V-Go at the 14 -month visit compared to $17 \%$ at baseline $(p<0.001)$.

In the cohort of patients naïve to insulin at baseline $(n=23)$, A1C reductions were significant at all time points and there was a mean \pm $\mathrm{SE}$ reduction in $\mathrm{A} 1 \mathrm{C}$ of $1.79 \pm 0.55 \%, p=0.002$ from baseline to the 14-month visit. For patients prescribed insulin at baseline, A1C was also significantly reduced at all time points compared to baseline (Fig. 2).

In addition, TDD of insulin was significantly reduced (Fig. 3). There were significant decreases in mean \pm SE TDD with V-Go of $21 \pm$ 3.8 units/day after 2 months, $20 \pm$ 3.8 units/day after 6 months, $16 \pm 4.0$ units/day after 10 months, and $17 \pm 4.5$ units/day after 14 months compared to baseline $(p<0.0001)$. Of the 103 enrolled patients, seven patients (of which six were prescribed basal-bolus MDI at baseline) required supplemental insulin which is included in reported TDD.

Among patients prescribed a basal-bolus MDI regimen at baseline $(n=58)$, the reduction in insulin with V-Go was even more pronounced. There was a decrease in mean \pm SE TDD of $31 \pm 3.9$ units/day, $p<0.0001$ at the 6-month visit compared to baseline, and after 14 months the decrease in mean TDD was $29 \pm 5.0$ units/day, $p<0.0001$.

Comparison of patients prescribed concomitant NIGLM at baseline and at 14 months (Table 3) supports a decrease in prescribed NIGLM over time across the overall population and when stratified by all patients prescribed insulin. Overall, NIGLM were reduced across all classes with the exception of the SGLT-2 inhibitor class, which did increase from $5 \%$ of patients to $16 \%$. 
Table 1 Baseline characteristics

\begin{tabular}{|c|c|c|c|}
\hline & $\begin{array}{l}\text { All patients } \\
(N=103)\end{array}$ & $\begin{array}{l}\text { All insulin patients }{ }^{\mathbf{a}} \\
(n=80)\end{array}$ & $\begin{array}{l}\text { Basal-bolus (MDI) patients } \\
(n=58)\end{array}$ \\
\hline \multicolumn{4}{|l|}{ Gender } \\
\hline Female & $47(46)$ & $33(41)$ & $20(34)$ \\
\hline Male & $56(54)$ & $47(59)$ & $38(66)$ \\
\hline Age, years & $63 \pm 11$ & $64 \pm 10$ & $64 \pm 10$ \\
\hline Range, years & $33-87$ & $33-87$ & $33-87$ \\
\hline \multicolumn{4}{|l|}{ Race } \\
\hline Caucasian & $75(73)$ & $59(74)$ & $44(76)$ \\
\hline Black & $21(20)$ & $16(20)$ & $10(17)$ \\
\hline Asian & $4(4)$ & $2(3)$ & $1(2)$ \\
\hline $\begin{array}{l}\text { Native Hawaiian/Pacific } \\
\text { Islander }\end{array}$ & $1(1)$ & $1(1)$ & $1(2)$ \\
\hline Undetermined & $2(2)$ & $2(2)$ & $2(4)$ \\
\hline Ethnicity, Hispanic & $2(2)$ & $2(3)$ & $2(3)$ \\
\hline \multicolumn{4}{|l|}{ Type of diabetes } \\
\hline Type 1 & $4(4)$ & $3(4)$ & $2(3)$ \\
\hline Type 2 & $99(96)$ & $77(96)$ & $56(97)$ \\
\hline Weight, kg & $94.4 \pm 22.3$ & $95.8 \pm 21.6$ & $98.9 \pm 22.3$ \\
\hline Range, kg & $44.3-153.4$ & $59.5-153.4$ & $59.5-153.4$ \\
\hline BMI, $\mathrm{kg} / \mathrm{m}^{2}$ & $31.98 \pm 6.36$ & $32.37 \pm 6.24$ & $32.88 \pm 6.50$ \\
\hline $\mathrm{A} 1 \mathrm{C}, \%$ & $9.80 \pm 2.01$ & $9.79 \pm 2.18$ & $9.73 \pm 2.25$ \\
\hline \multicolumn{4}{|c|}{ Comorbidities and complications } \\
\hline Hyperlipidemia & $80(78)$ & $64(80)$ & $46(79)$ \\
\hline Hypertension & $68(66)$ & $51(64)$ & $39(67)$ \\
\hline Neuropathy & $34(33)$ & $26(33)$ & $17(29)$ \\
\hline Coronary artery disease & $17(17)$ & $16(20)$ & $14(24)$ \\
\hline Hypercholesterolemia & $12(12)$ & $10(13)$ & $9(16)$ \\
\hline Renal disease & $8(8)$ & $5(6)$ & $4(7)$ \\
\hline Congestive heart failure & $5(5)$ & $5(6)$ & $3(5)$ \\
\hline Retinopathy & $4(4)$ & $2(3)$ & $2(3)$ \\
\hline
\end{tabular}

Data are $n(\%)$ or mean \pm SD unless otherwise noted. Percentages may not add up to $100 \%$ because of rounding $A I C$ glycated hemoglobin, $B M I$ body mass index, $M D I$ multiple daily injections of insulin

a Includes basal-only, premix, prandial, and basal-bolus insulin regimens

b Includes only patients prescribed basal-bolus regimens 
Table 2 Baseline prescribed treatment regimen

\begin{tabular}{|c|c|c|c|}
\hline & $\begin{array}{l}\text { All patients } \\
(N=103)\end{array}$ & $\begin{array}{l}\text { All insulin patients } \\
(n=80)\end{array}$ & $\begin{array}{l}\text { Basal-bolus (MDI) patients } \\
(n=58)\end{array}$ \\
\hline Diet and exercise only & $1(1)$ & - & - \\
\hline $\begin{array}{l}\text { Non-insulin glucose lowering meds } \\
\text { (NIGLM) only }\end{array}$ & $22(21)$ & - & - \\
\hline Insulin \pm NIGLM & $80(78)$ & $80(100)$ & $58(100)$ \\
\hline Basal-bolus & $58(56)$ & $58(73)$ & $58(100)$ \\
\hline Basal-only & $18(18)$ & $18(23)$ & - \\
\hline Premixed & $3(3)$ & $3(4)$ & - \\
\hline Prandial only & $1(1)$ & $1(1)$ & - \\
\hline Insulin TDD, units/day & $84 \pm 44$ & $84 \pm 44$ & $99 \pm 40$ \\
\hline TDD range, units/day & $0-200$ & $10-200$ & $32-200$ \\
\hline Insulin TDD, units $/ \mathrm{kg}$ & $0.88 \pm 0.45$ & $0.88 \pm 0.45$ & $1.03 \pm 0.42$ \\
\hline
\end{tabular}

Data are $n(\%)$ or mean \pm SD unless otherwise noted. Percentages may not add up to $100 \%$ because of rounding $M D I$ multiple daily injections of insulin, NIGLM non-insulin glucose lowering medication, TDD total daily dose of insulin ${ }^{a}$ Includes basal-only, premix, prandial and basal-bolus insulin regimens

${ }^{b}$ Includes only patients prescribed basal-bolus regimens

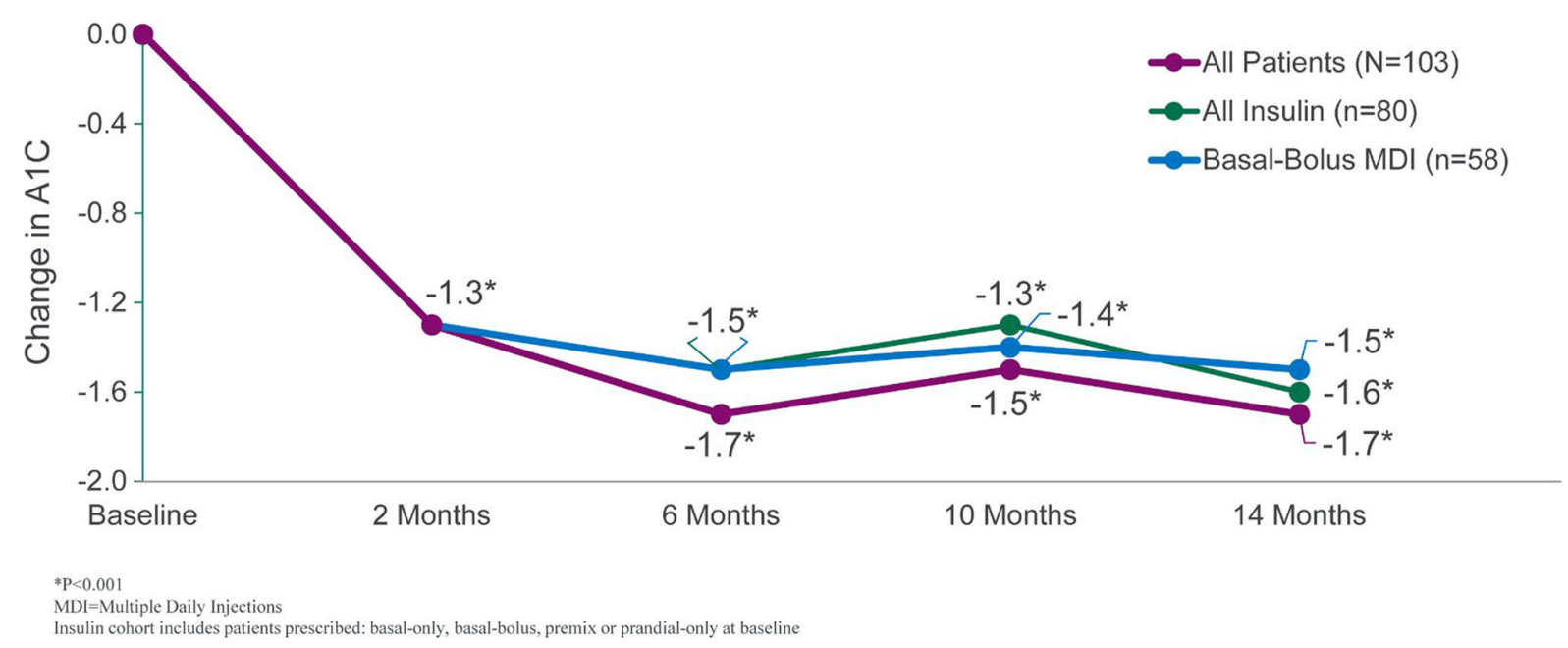

Fig. 2 Change in glycated hemoglobin (A1C). Patients experienced statistically significant decreases in A1C at all follow-up visits compared to baseline after switching to V-Go for insulin delivery

\section{Direct Pharmacy Budget Impact}

Results of the analysis of diabetes-related direct pharmacy costs in patients administering insulin with MDI at baseline are shown in Table 4 . The cost savings from the decrease in TDD of insulin more than offset the cost of V-Go, with an overall decrease of \$25 per 


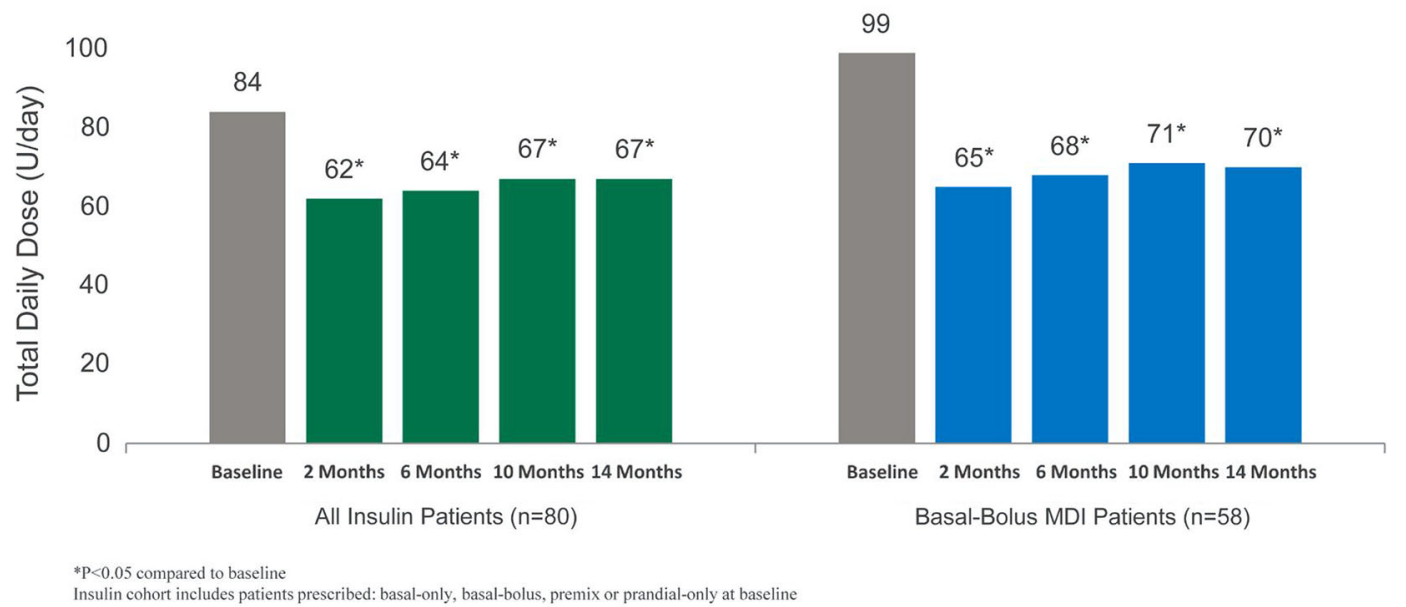

Fig. 3 Insulin total daily dose (TDD). Patients who used insulin at baseline, as well as the cohort of patients who used a basal-bolus MDI regimen at baseline experienced statistically significant decreases in TDD of insulin at all follow-up visits compared to baseline after switching to V-Go for insulin delivery

patient per month after switching from a basalbolus MDI regimen delivered by insulin pens and/or syringes to V-Go.

\section{Discontinuations and Lost to Follow-up}

At 6 months, $88 \%$ of patients had documented continued V-Go use, 5\% had documented discontinuation, and $7 \%$ were lost to follow-up. At 14 months, $68 \%$ of patients had continued V-Go use, $14 \%$ had discontinued, and $18 \%$ were lost to follow-up. Reasons documented for discontinuation were due to insurance coverage/cost $(n=6)$, insufficient insulin volume with V-Go $(n=2)$ and skin irritation, no longer requiring insulin, or patient preference $(n=1$ each). The reason for $\mathrm{V}-\mathrm{Go}$ discontinuation was not reported in three patients.

\section{Safety}

By the 14-month visit, the overall study population experienced a mean weight gain of $3.18 \mathrm{~kg}, p=0.029$ from baseline. Patients prescribed insulin at baseline $(n=80)$ experienced a mean weight gain of $2.04 \mathrm{~kg}, p=0.200$. Patients prescribed a basal-bolus MDI regimen prior to V-Go experienced a change in weight of $0.26 \mathrm{~kg}, p=0.897$. The incidence of patient- reported hypoglycemia documented at baseline was similar to the documented incidence at 14 months. No device malfunctions were reported. One subject reported skin irritation related to V-Go adhesive as a reason for discontinuation.

\section{DISCUSSION}

The current study demonstrated that V-Go use was associated with improved A1C that was sustained for over a year in a population of uncontrolled patients in a real-world setting. V-Go was associated with a $1.3-1.7 \%$ reduction in A1C from baseline over the course of the study. The population studied had multiple comorbidities, and nearly $60 \%$ of patients had a baseline $\mathrm{A} 1 \mathrm{C}>9 \%$ making the reduction in A1C even more noteworthy. Two-thirds of patients with baseline A1C $>9 \%$ achieved $\mathrm{A} 1 \mathrm{C} \leq 9 \%$ after 6 months of $\mathrm{V}$-Go use. The population with $\mathrm{A} 1 \mathrm{C}>9 \%$ is at high risk for complications, and improved glycemic control has well-documented clinical and economic benefits. Every $1 \%$ reduction in A1C can be expected to decrease the risk of microvascular complications by $37 \%$ [21], and costs are lower for patients with good glycemic control [22]. The improvements in A1C seen in the study 
Table 3 Concomitant non-insulin glucose-lowering medications over time

\begin{tabular}{|c|c|c|c|c|c|c|}
\hline & \multicolumn{2}{|c|}{ All patients $(N=103)$} & \multicolumn{2}{|c|}{ All insulin patients ${ }^{\mathrm{a}}(n=80)$} & \multicolumn{2}{|c|}{$\begin{array}{l}\text { Basal-bolus (MDI) patients } \\
(n=58)\end{array}$} \\
\hline & Baseline & 14 months & Baseline & 14 months & Baseline & 14 months \\
\hline Concomitant NIGLM & $69(67)$ & $57(55)$ & $47(59)$ & $42(53)$ & $29(50)$ & $29(50)$ \\
\hline Metformin & $48(47)$ & $39(38)$ & $30(38)$ & $24(30)$ & $19(33)$ & $17(29)$ \\
\hline GLP-1 receptor agonist & $28(27)$ & $18(17)$ & $19(24)$ & $16(20)$ & $10(17)$ & $10(17)$ \\
\hline Sulfonylurea & $14(14)$ & $1(<1 \%)$ & $5(6)$ & $1(1)$ & $2(3)$ & $1(2)$ \\
\hline DPP-4 inhibitor & $8(8)$ & $1(<1 \%)$ & $4(5)$ & $1(1)$ & $0(0)$ & $1(2)$ \\
\hline TZD & $6(6)$ & $2(2)$ & $5(6)$ & $2(3)$ & $4(7)$ & $2(3)$ \\
\hline DPP-4 I/metformin & $5(5)$ & $0(0)$ & $3(4)$ & $0(0)$ & $1(2)$ & $0(0)$ \\
\hline SGLT-2 inhibitor & $5(5)$ & $16(16)$ & $3(4)$ & $13(16)$ & $2(3)$ & $7(12)$ \\
\hline Metformin/sulfonylurea & $2(2)$ & $0(0)$ & $1(1)$ & $0(0)$ & $1(2)$ & $0(0)$ \\
\hline \multicolumn{7}{|l|}{ Number of NIGLM } \\
\hline 0 & $34(33)$ & $45(44)$ & $33(41)$ & $37(46)$ & $29(50)$ & $28(48)$ \\
\hline 1 & $35(34)$ & $43(42)$ & $30(38)$ & $32(40)$ & $22(38)$ & $24(41)$ \\
\hline 2 & $23(22)$ & $11(11)$ & $12(15)$ & $8(10)$ & $4(7)$ & $4(7)$ \\
\hline 3 & $9(9)$ & $4(4)$ & $4(5)$ & $3(4)$ & $3(5)$ & $2(3)$ \\
\hline 4 & $2(2)$ & $0(0)$ & $1(1)$ & $0(0)$ & $0(0)$ & $0(0)$ \\
\hline
\end{tabular}

Data are $n(\%)$. Percentages may not add up to $100 \%$ because of rounding

$D P P$ dipeptidyl peptidase, GLP-1 glucagon like peptide, $M D I$ multiple daily injections, $N I G L M$ non-insulin glucoselowering medication, $S G L T$ sodium glucose linked transporter, $T Z D$ thiazolidinediones

a Includes basal-only, premix, prandial, and basal-bolus insulin regimens

b Includes only patients prescribed basal-bolus regimens

were not attributable to changes in concomitant NIGLM; at baseline 33\% of patients used two or more concomitant medications and by 14 months this was reduced by more than half (15\%).

Appropriate insulin use can help patients achieve glycemic targets; however, barriers to insulin use may delay initiation of insulin or affect adherence to prescribed therapy [8, 23-25]. Adherence has a direct impact on glycemic control [8], and lack of adherence can lead to serious complications that may require hospitalization [25]. Advances in insulin delivery mode including the fully mechanical basalbolus insulin delivery device have addressed barriers to insulin use. Reasons patients report for missing insulin doses include injection frequency, having to plan daily activities around injections, embarrassment around injections, and injection pain. These barriers to adherence often pertain specifically to mealtime dosing, which is a prevalent issue considering a study conducted by Holman et al. showed that $82 \%$ of patients on basal therapy required mealtime insulin boluses within 3 years to reach targets [26]. The insulin pen addresses some of the issues and has increased adherence [27]. But insulin pens do not address patients' objection to injection frequency, the need to inject while out of the house, and embarrassment around conspicuous injections. V-Go is an innovative, convenient, and flexible insulin delivery option 
Table 4 Diabetes-related direct pharmacy costs in patients prescribed basal-bolus at baseline

\begin{tabular}{|c|c|c|c|c|}
\hline \multirow{2}{*}{$\begin{array}{l}\text { Costs per patient per month } \\
\text { NIGLM }\end{array}$} & \multicolumn{2}{|c|}{ Baseline basal-bolus (MDI), $N=58$} & \multicolumn{2}{|c|}{ On V-Go (14 months), $N=58$} \\
\hline & & $\$ 176$ & & $\$ 187$ \\
\hline Prescribed insulin TDD & $99 \mathrm{U}$ & $\$ 898$ & $70 \mathrm{U}^{*}$ & $\$ 556^{*}$ \\
\hline Pen needles/syringes/V-Go & 4 pen needles or syringes & $\$ 49$ & $1 \mathrm{~V}-\mathrm{Go}^{*}$ & $\$ 332$ \\
\hline Total diabetes therapeutic costs & & $\$ 1122$ & & $\$ 1097$ \\
\hline Change in A1C from baseline & & & & $-1.5 \%^{\mathrm{a}}$ \\
\hline
\end{tabular}

Data are means and all costs are normalized on the basis of 30 days and rounded to the nearest dollar, based on WAC $=$ Wholesale Acquisition Cost based on ProspectoRx [database online]. Tampa, FL: Elsevier, Gold Standard, Inc.; 2014. https://prospectorx.com/Home.aspx. Accessed Jan 1, 2018

$A I C$ glycated hemoglobin, $M D I$ multiple daily injections of insulin, NIGLM non-insulin glucose-lowering medications, $T D D$ total daily dose

*TDD includes supplemental insulin prescribed in 6 patients and delivery costs account for pen needles/syringes as applicable

${ }^{a}$ Change in A1C reflective of change in glycemic control at study end in this cohort

designed to replace MDI and simplify basal-bolus therapy [28]. Prandial boluses are delivered through the press of two buttons, which can be done discreetly through clothing. In a small survey, V-Go was perceived by patients to be easy to use, discreet, and comfortable to wear [19]. Multiple studies support the effectiveness of V-Go in significantly reducing A1C, demonstrating decreases in mean A1C of $1.2-2.0 \%$ [16-20, 28, 29]. In a study by Rosenfeld et al., mean A1C decreased by $1.2 \%$ after switching to V-Go, and after V-Go was stopped, A1C increased by $0.6 \%$. In addition, patients in the study reported good adherence with V-Go, with an average of only one missed mealtime bolus per month reported [19].

In our practice, we consider insulin therapy with V-Go for patients initiating basal-bolus therapy who desire the convenience offered by V-Go, and also in patients who are not controlled using MDI whose adherence is in question. We consider V-Go for both patients with type 1 and type 2 diabetes; however, V-Go is used predominantly in type 2 patients and, as is reflected of the study data, V-Go is not intended to replace an electronic insulin pump. It is considered for patients who do not require routine adjustments to basal rate, have basal requirements within the standard range offered by V-Go, and who do not require bolus doses in increments smaller than 2 units/day.
The current study results support not only that basal-bolus insulin therapy is effective but also that method of insulin administration is important. A cohort of patients in the study was already using a basal-bolus MDI regimen at baseline, and this population achieved a $1.48 \%$ reduction in A1C after 6 months of V-Go use, which was sustained at 14 months with a $1.53 \%$ reduction in A1C from baseline. This reduction was achieved with a significantly lower TDD of insulin-a 31\% decrease from baseline after 6 months, and a $29 \%$ decrease from baseline after 14 months, with relatively few changes across NIGLM. This improvement in glycemic control with a lower TDD of insulin after changing from a basal-bolus MDI regimen to V-Go can be attributed to the continuous subcutaneous insulin delivery of the preset basalrate, and to the fact that having insulin always available can support more timely insulin administration and increased compliance, which can result in improved glucose coverage. Reductions of $20-30 \%$ in insulin requirements have been demonstrated when more efficient insulin delivery modes are used as seen in the landmark Opt2mise trial and a study conducted by Bode et al., which are both consistent with the reduction in TDD seen in patients switching from basal-bolus MDI to V-Go for basal-bolus therapy [30, 31]. 
Cost can be a barrier to insulin adoption and adherence. In the cohort of patients using a MDI regimen at baseline, there was a net saving in the direct pharmacy cost of diabetes therapy with use of V-Go. Previous research has shown similar results, with a direct pharmacy costs net saving of $\$ 55.70$ per month with V-Go over MDI [17].

In the current study, there was no patientreported increase in hypoglycemia documented with use of V-Go, and the weight increase in the overall population was within expected range for insulin use. There was no significant change in weight for patients switching from basal-bolus MDI to V-Go.

Persistence to therapy is also critical to glycemic control. Research conducted by Bonafede et al. investigated persistence to mealtime insulin using a research database. They found that persistence to mealtime insulin was low; $42 \%$ of patients were persistent after 12 months [32]. In the current study, after approximately 14 months only $14 \%$ of patients had documented discontinued V-Go use, with $68 \%$ of patients confirmed as persistent, which supports the strong acceptance of V-Go. This persistence is reflected in the durable decrease in A1C, with a reduction of $1.69 \%$ between baseline and 6 months, and a reduction of $1.67 \%$ between baseline and 14 months.

Empowering patients to take more control through patient-centered insulin regimens and patient-friendly delivery systems may improve control and reduce complications [27]. V-Go offers a simplified, effective method to deliver basal-bolus therapy, which eliminated the need for MDI and allows for discreet mealtime bolus doses.

\section{Limitations}

Several limitations should be considered when interpreting the results of this study. Considering this was a retrospective observational study with a pre-post design, only associations can be determined. Despite the lack of ability to provide causal evidence of improved $\mathrm{A} 1 \mathrm{C}$ and decreased TDD with V-Go therapy, our study provides important information on the expected improvements in A1C with V-Go therapy during the course of normal clinical practice.

Secondly, cost calculations were based on prescribed medications documented in the medical records and may not be reflective of actual adherence and fulfillment may have differed. Thirdly, to be included in the analysis patients were required to have at least one follow-up office visit with an A1C result recorded, so the data in our study may not be representative of all patients initiating V-Go therapy and may be influenced by patients with a propensity to adhere to medication. Additionally, considering that a patient visit schedule was not dictated, it is possible that patients considered lost to follow-up had not yet returned for the visit by the time the data collection period ended.

Finally, the prevalence of actual hypoglycemia may have differed as patient self-reports were evaluated in the study. These data represent real-world experience with no educational initiatives, special procedures, training, and/or practice changes implemented during the study period that could have contributed to the results. The data recording process was consistent across baseline and on V-Go.

\section{CONCLUSION}

Patients with sub-optimally controlled diabetes were safely transitioned to V-Go and achieved significant and sustained A1C improvements with a reduction in TDD of insulin from baseline. V-Go is an advancement in insulin delivery that can address multiple barriers to insulin initiation and adherence and ultimately improve patient outcomes.

\section{ACKNOWLEDGEMENTS}

The authors wish to thank the participants in the study.

Funding. Sponsorship for this study and article processing charges were funded by Valeritas, Inc, Bridgewater, NJ. All authors had 
full access to all of the data in this study and take complete responsibility for the integrity of the data and the accuracy of the data analysis.

Editorial Assistance. Editorial assistance in the preparation of this article was provided by Maria Paluselli, founder of Panaceum Clinical, LLC. Support for this assistance and article publication fees were funded by Valeritas, Inc.

Authorship. All named authors meet the International Committee of Medical Journal Editors (ICMJE) criteria for authorship for this article, take responsibility for the integrity of the work as a whole, and have given their approval for this version to be published.

Prior Presentation. Accepted abstracts were presented at four poster sessions: 2016 American Diabetes Association (ADA) meeting (two posters), 2016 Academy of Managed Care Pharmacy (AMCP) meeting, and 2016 American Association of Clinical Endocrinologists (AACE) meeting.

Disclosures. David Sutton is a consultant and speaker for Valeritas Inc. Charissa D. Higdon has received funding from Valeritas, Inc for data extraction associated with research. Carla Nikkel is an employee and stockholder of Valeritas, Inc. Karrie A. Hilsinger was an employee of Valeritas, Inc. at the time of study conduct. Her current affiliation is Mallinckrodt Pharmaceuticals, Landing, NJ, USA.

Compliance with Ethics Guidelines. This study was reviewed and approved by Allendale Investigational Review Board prior, and a waiver of informed consent was granted. All procedures performed were in accordance with the ethical standards of the institutional and/or national research committee and with the 1964 Declaration of Helsinki and its later amendments or comparable ethical standards.

Data Availability. The data sets generated and analyzed during the current study are available from the corresponding author on reasonable request.
Open Access. This article is distributed under the terms of the Creative Commons Attribution-NonCommercial 4.0 International License (http://creativecommons.org/licenses/ by-nc/4.0/), which permits any noncommercial use, distribution, and reproduction in any medium, provided you give appropriate credit to the original author(s) and the source, provide a link to the Creative Commons license, and indicate if changes were made.

\section{REFERENCES}

1. Menke A, Casagrande S, Geiss L, Cowie CC. Prevalence of and trends in diabetes among adults in the United States, 1988-2012. JAMA. 2015;314(10):1021-9.

2. CDC Online Newsroom [press release]. Number of Americans with diabetes projected to double or triple by 2050; October 22, 2010. https://www.cdc. gov/media/pressrel/2010/r101022.html. Accessed 11 Mar 2017.

3. Boyle JO, Thompson TJ, Gregg EW, Barker LE, Williamson DF. Projection of the year 2050 burden of diabetes in the US adult population: dynamic modeling of incidence, mortality, and prediabetes prevalence. Popul Health Metr. 2010;22(8):29. https://doi.org/10.1186/1478-7954-8-29.

4. Centers for Disease Control and Prevention. National diabetes statistics report: estimates of diabetes and its burden in the United States. 2014. Atlanta: US Department of Health and Human Services; 2014. https://www.cdc.gov/diabetes/pdfs/ data/2014-report-estimates-of-diabetes-and-itsburden-in-the-united-states.pdf. Accessed 11 Mar 2017.

5. Lipska KJ, Yao X, Herrin J, et al. Trends in drug utilization, glycemic control, and rates of severe hypoglycemia, 2006-2013. Diabetes Care. 2017;40(4):468-75.

6. Garber AJ, Abrahamson MJ, Barzilay JI, et al. Association of Clinical Endocrinologists (AACE); American College of Endocrinology (ACE). Consensus statement by the American Association of Clinical Endocrinologists and American College of Endocrinology on the comprehensive type 2 diabetes management algorithm-2017 executive summary. Endocr Pract. 2017;23(2):207-38.

7. American Diabetes Association. Standards of medical care in diabetes-2017. Chapter 8: 
pharmacologic approaches to glycemic treatment. Diabetes Care. 2017;40(Supplement 1):S64-74.

8. Peyrot M, Barnett AH, Meneghini LF, SchummDraeger PM. Factors associated with injection omission/non-adherence in the Global Attitudes of Patients and Physicians in Insulin Therapy study. Diabetes Obes Metab. 2012;14(12):1081-7.

9. Kim S. Burden of hospitalizations primarily due to uncontrolled diabetes: implications of inadequate primary healthcare in the United States. Diabetes Care. 2007;30:1281-2.

10. Brown JB, Pedula KL, Bakst AW. The progressive cost of complications in type 2 diabetes mellitus. Arch Intern Med. 1999;159:1873-80.

11. Campbell KR. Recommendations for improving adherence to type 2 diabetes mellitus therapy-focus on optimizing insulin-based therapy. Am J Manag Care. 2012;18(3):S55-61.

12. Diabetes.co.uk. History of insulin. https://www. diabetes.co.uk/insulin/history-of-insulin.html. Accessed 11 Mar 2018.

13. Lee WC, Balu S, Cobden D, Joshi AV, Pashos CL. Medication adherence and the associated healtheconomic impact among patients with type 2 diabetes mellitus converting to insulin pen therapy: an analysis of third-party managed care claims data. Clin Ther. 2006;28(10):1712-25.

14. Baser O, Bouchard J, DeLuzio T, Henk H, Aagren M. Assessment of adherence and healthcare costs of insulin device (FlexPen) versus conventional vial/ syringe. Adv Ther. 2010;27(2):94-104.

15. Valeritas. $\mathrm{V}-\mathrm{Go}^{\circledR}$ : instructions for patient use. https://www.go-vgo.com/sites/default/files/upload/ instructions-for-patient-use.pdf. Accessed 11 Mar 2018.

16. Lajara R, Fetchick DA, Morris TL, Nikkel C. Use of $\mathrm{V}-\mathrm{Go}^{\circledR}$ insulin delivery device in patients with suboptimally controlled diabetes mellitus: a retrospective analysis from a large specialized diabetes system. Diabetes Ther. 2015;6(4):531-45.

17. Lajara R, Davidson JA, Nikkel CC, Morris TL. Clinical and cost-effectiveness of insulin delivery with $\mathrm{V}-\mathrm{Go}^{\circledR}$ disposable insulin delivery device versus multiple daily injections in patients with type 2 diabetes inadequately controlled on basal insulin. Endocr Pract. 2016;22(6):726-35.

18. Lajara R, Nikkel C. Practical Considerations for switching to $\mathrm{V}-\mathrm{Go}^{\circledR}{ }^{\circledR}$ for insulin delivery in patients with type 2 diabetes. Pract Diabetol. 2016;5:10-5.
19. Rosenfeld CR, Bohannon NJ, Bode B, et al. The V-Go insulin delivery device used in clinical practice: patient perception and retrospective analysis of glycemic control. Endocr Pract. 2012;18(5):660-7.

20. Johns BR, Jones TC, Sink JH 2nd, Cooke CE. Realworld assessment of glycemic control after $\mathrm{V}-\mathrm{Go}^{\circledR}$ initiation in an endocrine practice in the southeastern United States. J Diabetes Sci Technol. 2014;8(5):1060-1.

21. Stratton IM, Adler AI, Neil HAW, et al. Association of glycaemia with macrovascular and microvascular complications of type 2 diabetes (UKPDS 35): prospective observational study. BMJ. 2000;321:405-12.

22. Oglesby AK, Secnik K, Barron J, Al-Zakwani I, Lage MJ. The association between diabetes related medical costs and glycemic control: a retrospective analysis. Cost Eff Resour Alloc. 2006;16(4):1.

23. Peyrot M, Rubin RR, Kruger DF, Travis LB. Correlates of insulin injection omission. Diabetes Care. 2010;33(2):240-5.

24. Petznick AM. Identifying and addressing barriers to insulin acceptance and adherence in patients with type 2 diabetes mellitus. J Am Osteopath Assoc. 2013;113(4 Suppl 2):S6-16 (Erratum in: J Am Osteopath Assoc. 2013;113(7):507).

25. Wild $\mathrm{H}$. The economic rationale for adherence in the treatment of type 2 diabetes mellitus. Am J Manag Care. 2012;18(3 Suppl):S43-8.

26. Holman RR, Farmer AJ, Davies MJ, et al. Three-year efficacy of complex insulin regimens in type 2 diabetes. N Engl J Med. 2009;361:1736-47.

27. LaSalle JR. Empowering patients during insulin initiation: a real-world approach. J Am Osteopath Assoc. 2010;110(2):69-78.

28. Winter A, Lintner M, Knezevich E. V-Go insulin delivery system versus multiple daily insulin injections for patients with uncontrolled type 2 diabetes mellitus. J Diabetes Sci Technol. 2015;9(5):1111-6.

29. Lajara R, Nikkel C, Abbott S. The clinical and economic impact of the $\mathrm{V}$-Go ${ }^{\circledR}$ disposable insulin delivery device for insulin delivery in patients with poorly controlled diabetes at high risk. Drugs Real World Outcomes. 2016;3(2):191-9.

30. Reznik Y, Cohen O, Aronson R, et al. Insulin pump treatment compared with multiple daily injections for treatment of type 2 diabetes (OpT2mise): a randomised open-label controlled trial. Lancet. 2014;384(9950):1265-72. 
31. Bode BW, Sabbah HT, Gross TM, Fredrickson LP, Davidson PC. Diabetes management in the new millennium using insulin pump therapy. Diabetes Metab Res Rev. 2002;18(Suppl 1): S14-20.
32. Bonafede MM, Kalsekar A, Pawaskar M, et al. Insulin use and persistence in patients with type 2 diabetes adding mealtime insulin to a basal regimen: a retrospective database analysis. BMC Endocr Disord. $2011 ; 12(11): 3$. 